\title{
Serum levels of urokinase-type plasminogen activator in healthy dogs and oncologic canine patients
}

Sofia C. Ramos ${ }^{1}$, Augusto J. de Matos ${ }^{2,3}$, João Niza Ribeiro4,5, Liliana R. Leite-Martins², Rui R. F. Ferreira ${ }^{3,6}$, Inês Viegas ${ }^{1}$ and Andreia A. Santos ${ }^{1,3}$

1. Department of Veterinary Clinics, Faculty of Veterinary Medicine of the University Lusófona of Humanities and Technologies, Campo Grande 376, Lisbon, Portugal; 2. Department of Veterinary Clinics of the Biomedical Sciences Institute of Abel Salazar (ICBAS), University of Porto, R. Jorge Viterbo Ferreira no. 228, Porto, Portugal; 3. Animal Science and Study Centre/Food and Agrarian Sciences and Technologies Institute (CECA/ICETA), P. Gomes Teixeira, Portugal; 4. Department of Population Studies, Biomedical Sciences Institute of Abel Salazar (ICBAS), University of Porto, R. Jorge Viterbo Ferreira no. 228, Porto, Portugal; 5. Institute of Public Health, University of Porto, R. das Taipas 135, Porto, Portugal; 6. Animal Blood Bank (BSA), R. Jorge Viterbo Ferreira no. 228, Porto, Portugal.

Corresponding author: Andreia A. Santos, e-mail: aasantos81@sapo.pt

Co-authors: SCR: sofiachichorro.92@gmail.com, AJdeM: ajmatos@icbas.up.pt, JNR: nizaribeiro@gmail.com, LRLM: Imartins@icbas.up.pt, RRFF: ruiferreira@bsanimal.com, IV: inesviegas@gmail.com Received: 03-03-2017, Accepted: 27-06-2017, Published online: 14-08-2017

doi: 10.14202/vetworld.2017.918-923 How to cite this article: Ramos SC, de Matos AJ, Ribeiro JN, Leite-Martins LR, Ferreira RRF, Viegas I, Santos AA (2017) Serum levels of urokinase-type plasminogen activator in healthy dogs and oncologic canine patients, Veterinary World, 10(8): 918-923.

\begin{abstract}
Aim: Urokinase plasminogen activator (uPA) has been scarcely studied in veterinary oncology. The aim of this study was to determine the uPA serum concentrations in healthy and oncologic canine patients and to investigate its potential value as a tumor biomarker.
\end{abstract}

Materials and Methods: Serum uPA concentrations of healthy and oncologic canine patients were measured by enzymelinked immunosorbent assay. Their relationships with the dogs' health status and tumor characteristics were analyzed through ANOVA and independent t-test.

Results: There were no significant differences between mean serum values ( \pm standard deviation) of healthy dogs $(0.19 \pm 0.13 \mathrm{ng} / \mathrm{ml})$ and oncologic canine patients $(0.22 \pm 0.33 \mathrm{ng} / \mathrm{ml})$, or between dogs with benign or malignant tumors, and with or without metastases, although the latter tended to show higher uPA serum levels.

Conclusion: This is the first study describing the uPA serum levels in dogs. Although its results do not support uPA as a tumor biomarker, higher uPA levels in dogs with metastatic neoplasms may reflect the role of the enzyme in tumor progression.

Keywords: biomarker, dogs, neoplasms, serum, urokinase plasminogen activator.

\section{Introduction}

An early detection of a neoplasm enhances the probability of therapeutic success, highlighting the importance of biomarkers identification [1]. Multiple cancer markers have been identified in human medicine and used in clinical practice, such as prostate-specific antigen in prostatic cancer [2] and steroid hormone receptors in breast cancer [3]. Members of the urokinase plasminogen activator system (uPAS) are also examples of potential cancer biomarkers related with prognosis that has been associated with several human neoplasms [4]. However, cancer biomarkers are scarcely described in veterinary medicine.

The uPAS has been involved in a variety of physiological events such as wound healing, mammary

Copyright: Ramos, et al. Open Access. This article is distributed under the terms of the Creative Commons Attribution 4.0 International License (http://creativecommons.org/licenses/by/4.0/), which permits unrestricted use, distribution, and reproduction in any medium, provided you give appropriate credit to the original author(s) and the source, provide a link to the Creative Commons license, and indicate if changes were made. The Creative Commons Public Domain Dedication waiver (http://creativecommons.org/ publicdomain/zero/1.0/) applies to the data made available in this article, unless otherwise stated. gland development/involution, and tissue regeneration $[5,6]$. Through events like proteolysis of the basal membrane and extracellular matrix (ECM), initiation of epithelial-mesenchymal transition and signal transduction pathways, the UPAS is also associated to pathological events, such as tumor angiogenesis, invasion, and metastasis [7-9]. The uPAS includes the urokinase plasminogen activator (uPA), its cell membrane receptor (uPAR), the tissue plasminogen activator and its two main inhibitors, the plasminogen activator inhibitor-1 (PAI-1) and -2 (PAI-2) [7,8].

When bound to the receptor, uPA catalyzes the conversion of inactive plasminogen into active plasmin [7], which can promote fibrinolytic processes [10] and proteolytic activities involved in the ECM degradation [11]. Plasmin can also participate in other regulatory mechanisms of cell behavior, such as secretion of cytokines and activation of pro-matrix metalloproteinases, promoting cellular migration and local invasion [12]. The active form of PAI-1 may inhibit uPA [6] and internalize the complex uPA/uPAR/PAI-1 for degradation [13], recycling UPAR that is then redistributed back to the cell surface, promoting its functions [14]. 
The secretion, function, and expression patterns of the UPAS members have been studied in a broad range of human malignancies [6], and they are examples of potential cancer biomarkers with prognostic and predictive values, already associated with several human neoplasms, such as mammary, pulmonary, and pancreatic cancer [4]. More specifically, and as an example, elevated levels of uPA catalytic activity in patients with breast cancer were associated with a shortened disease-free interval, comparing to those with lower levels of uPA activity [15-17]. Also in breast cancer, patients without lymph node metastasis and with elevated UPA and PAI-1 levels benefited from adjuvant treatment, while similar patients but with lower levels did not $[17,18]$.

Several studies indicate that the uPAS could be a promising therapeutic oncologic target $[4,8]$, and some of the proposed therapeutic models included the suppression of the uPAS components [19,20], the inhibition of their proteolytic activity [21,22], the interference between uPAR connection with the respective ligands [23,24] or with integrins [25], and also toxins directed to uPAS components [26,27]. However, understanding the interactions and functions of the uPA/uPAR complex are a challenging task, because the inhibition of its components seems to originate a functional compensation by other proteases, such as metalloproteinases [28].

uPA has been studied in human medicine in several sample types, including serum levels in patients with head and neck squamous cell carcinoma [29], breast cancer [30], ovarian cancer [31] and prostatic cancer [32], and their results suggest that uPA plays important roles in cancer evolution, particularly in processes such as angiogenesis and metastasis and might also be of prognostic and predictive value.

However, the UPAS is scarcely mentioned in veterinary medicine, and serum levels of uPA have never been determined in animals. uPA has been studied by immunohistochemical methods in some canine neoplasms, such as mammary tumors [33-35] and hemangiosarcomas [36,37]. Santos et al. [33,34] showed that both cancer cells and adjacent stroma of malignant mammary tumors significantly overexpressed uPA. In addition, the high expression of uPA by tumor stroma was significantly associated with several poor prognosis factors, such as higher histological grade, higher $\mathrm{Ki}-67$ indices, higher metastatic rate, and also with shorter overall and disease-free survival. Golshahi et al. [35], studying the same type of neoplasm, obtained the same results by showing that an elevated uPA stromal expression was associated with poor prognosis. Anwar et al. [37] demonstrated that uPA and UPAR were significantly associated with cancer cells proliferation in canine hemangiosarcomas. UPAR was also studied in canine prostatic proliferative disorders, which exhibited higher expressions comparing to normal prostatic tissues [38]. Overexpression of stromal uPAS members was also found in a feline giant cell tumor of bone [39]. Taken together, these results suggest that uPA contributes for tumor aggressiveness in canine patients and constitutes a relevant prognostic factor, supporting its potential value as a tumor biomarker and as a therapeutic target, as already demonstrated in human medicine.

The determination of cancer markers in serum may be more useful than immunohistochemistry methods for the clinical setting, by being a faster and less invasive approach that may allow an early identification of patients with cancer. Hence, this study was undertaken to address the value of uPA as a serum biomarker, to distinguish cancer patients from healthy dogs. The relationships between uPA levels and clinicopathological characteristics with prognostic relevance, such as neoplasm size, histologic grade and lymph nodes invasion/distant metastasis, were also studied. In the face of the scarcity of animal serum cancer biomarkers, this study aimed to shed an initial light on the potential of uPA as a candidate for such role.

\section{Materials and Methods}

\section{Ethical approval}

The study protocol was approved by the Ethics Committee of the Faculty of Veterinary Medicine, University Lusófona of Humanities and Technologies (FMV-ULHT) (N56/2014).

\section{Samples}

Blood samples were collected from both healthy dogs and canine patients diagnosed with benign and malignant neoplasms at the hospitals of two veterinary schools, FMV-ULHT, and Veterinary Hospital of Biomedical Sciences Institute of Abel Salazar of University of Porto (UPVet-ICBAS), after owner's informed consent. Some blood samples of control dogs were also collected at the Animal Blood Bank (BSA), Porto. From all dogs information such as age, weight and gender, past medical history and, when applicable, the tumor characteristics, such as type, location and size, was collected and registered. Dogs were grouped according to the canine clinical nutrition encyclopedia [40] in small (1-9.9 kg), medium (10-29.9 kg), and large breed dogs $(\geq 30 \mathrm{~kg})$. Cutaneous neoplasms were measured and grouped according to their largest dimension in three categories: $<3 \mathrm{~cm}, 3-5 \mathrm{~cm}$, and $>5 \mathrm{~cm}$.

All animals were older than 4 years old. The healthy Group A consisted of 21 dogs (12 females and 9 males) without previous neoplastic or inflammatory diseases, no clinical evidence of disease, and normal complete blood count and serum biochemistry. The tumor Group B included 20 dogs (11 females and 9 males) with cytologically and/or histologically confirmed neoplasms. Animals with concomitant inflammatory disease or that had been submitted to any therapeutic intervention were excluded from the study. The clinical staging was assessed in all Group B dogs, based on a complete physical examination, three 
thoracic radiographic views, a complete abdominal ultrasound evaluation, and cytology and/or biopsy of organs suspected of metastatic involvement.

Cytological and histological diagnoses were performed by three laboratories: Laboratory of Clinical Analysis and Histopathology of ULHT, Veterinary Pathology Laboratory of the Biomedical Sciences Institute of Abel Salazar (ICBAS), University of Porto (UP), and Cytology Diagnostic Services of ICBAS-UP.

\section{uPA measurement in serum}

Blood samples $(5 \mathrm{ml})$ were collected and introduced into a serum separator tube, allowed to clot for $8 \mathrm{~h}$ at $2-8^{\circ} \mathrm{C}$, and centrifuged at $3000 \mathrm{rpm}$ for $15 \mathrm{~min}$. Serum was removed and divided into four aliquots $\left(0.5 \mathrm{ml}\right.$ each), stored frozen at $-80^{\circ} \mathrm{C}$ until processing. All samples with visible moderate or intense hemolysis were excluded from the study.

The supernatant hemoglobin values were measured in all samples with mild hemolysis, to investigate if its presence could influence uPA levels. For that purpose, $0.02 \mathrm{ml}$ of serum was pipetted to cuvettes, subsequently introduced in a quantitative measuring device (Low Hemoglobin Analyzer Meter - Scott European Corporation), and values were recorded for further analysis.

The serum levels of uPA were measured using a canine-specific uPA sandwich enzyme-linked immunosorbent assay. The assays and data calculations were performed according to the manufacturer's instructions (MyBiosource - MBS020636). All samples were run in duplicate and optical densities (OD) were read spectrophotometrically at $450 \mathrm{~nm}$ in a microplate reader. The average OD of the Kit standard solutions was calculated and standard curves were established, using CurveExpert software (MyBiosource), from which the uPA serum concentrations were extrapolated.

\section{Statistical analysis}

All data were analyzed with IBM SPSS version 23. UPA serum concentrations of controls and cases were presented as means \pm standard deviation (SD). For the comparative analysis of uPA values between controls/neoplasms, benign/malignant, metastatic/nonmetastatic and variables related to the animal intrinsic characteristics, cutaneous neoplasm size and the presence of hemolysis, Student's t-test for independent samples and ANOVA were used. The significance level was established at $\mathrm{p}<0.05$.

\section{Results}

The mean serum uPA concentration of healthy dogs $( \pm \mathrm{SD})$ was $0.19 \mathrm{ng} / \mathrm{ml}( \pm 0.13)$. This group was composed by $85.7 \%$ large breed, $9.5 \%$ medium breed, and $4.8 \%$ small breed dogs. The concentrations were not significantly influenced by intrinsic characteristics such as gender, age, and weight (Figure-1).

The group of oncologic patients included 5 dogs affected by benign and 15 by malignant tumors, including 7 epithelial, 5 mesenchymal, 4 hematopoietic/lymphoreticular, 1 gonadal and 3 mixed neoplasms. Their mean serum uPA concentration $( \pm \mathrm{SD})$ was $0.22 \mathrm{ng} / \mathrm{ml}( \pm 0.33)$. The uPA concentrations were not significantly different between healthy and diseased patients or between dogs affected by benign or malignant neoplasms (Table-1).

In the malignant group, 3 cases had lymph node metastases, 1 had distant metastases and 3 had both. Due to the small number of cases, dogs with lymph node and/or distant metastases were grouped together for statistical analysis. There were no statistical differences between dogs with or without metastases (Table-1), although the uPA values from nonmetastatic cases were $65 \%$ lower comparing to the metastatic ones.

When dogs with cutaneous neoplasms $(n=10)$ were considered, there was no relationship between their uPA concentration and tumor size (Table-1). Finally, mild hemolysis did not significantly influence serum uPA values in either group (Table-1).

\section{Discussion}

Considering the several evidences of the uPA role in human cancer development and progression, the main goal of this study was to determine the serum concentrations of uPA in healthy dogs and to compare them with those of cancer patients. To the best of our knowledge, this is the first study addressing this goal in canine cancer patients.

The mean uPA value of healthy dogs $(0.19 \pm 0.13 \mathrm{ng} / \mathrm{ml})$ was lower than the concentrations described in humans $(0.56 \pm 0.16$ to $1.1 \pm 0.38 \mathrm{ng} / \mathrm{ml}$ ) [41-44]. uPA values may be species related, and perhaps uPA serum values in healthy canines are lower than in healthy humans. However, this hypothesis needs to be validated with a larger study. Nevertheless, similarly to what reported in human studies, canine uPA values seem to be independent of individual factors such as gender, age and weight $[44,45]$.

Healthy dogs had similar uPA concentrations to oncologic canine patients, suggesting that it is unsuitable as a serum biomarker of neoplastic disease. These results are concordant with some studies of human cancer, including head and neck squamous cell carcinoma [29] and pulmonary neoplasms [41]. However, a different conclusion emerged from studies in pancreatic/biliar neoplasms [42,43], ovarian [31], and prostate cancer [32], where significant differences in uPA serum values between healthy and oncologic patients were found. Such variances suggest that circulating uPA levels may be related to the neoplasms tissue of origin or tumor histological type. Supporting this hypothesis, other studies detected a lower uPA expression in certain human tumor types, such as basal cells carcinomas [46].

In addition, the uPA values of dogs with benign neoplasms were not significantly different from those of dogs with malignant neoplasms, although it is 


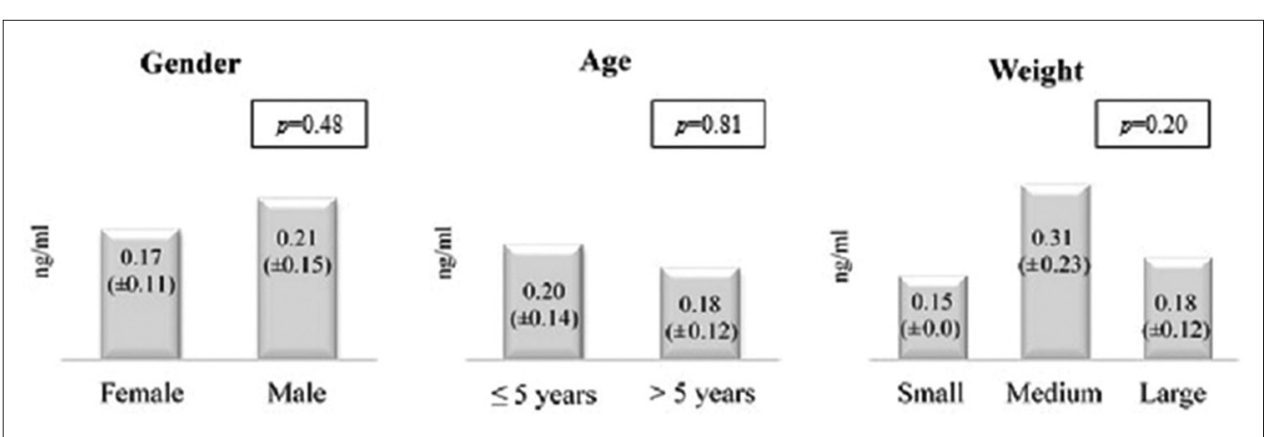

Figure-1: Mean urokinase plasminogen activator serum values ( $\mathrm{ng} / \mathrm{ml})$ ( \pm standard deviation) according to the intrinsic characteristics of healthy dogs.

Table-1: uPA serum concentrations in healthy dogs and in oncologic canine patients.

\begin{tabular}{|c|c|c|c|c|c|}
\hline \multirow[t]{2}{*}{ Variable } & \multirow[t]{2}{*}{ Mean uPA serum values \pm SD $(\mathrm{ng} / \mathrm{ml})$} & \multicolumn{2}{|c|}{ CI $(95 \%)$} & \multirow[t]{2}{*}{ p value } & \multirow{2}{*}{$\frac{\text { Animals }}{\mathrm{n}(\%)}$} \\
\hline & & Minimum & Maximum & & \\
\hline Healthy dogs & $0.19(0.13)$ & 0.13 & 0.25 & 0.67 & $21(51)$ \\
\hline Oncologic patients & $0.22(0.33)$ & 0.07 & 0.38 & & $20(49)$ \\
\hline Benign & $0.17(0.12)$ & 0.02 & 0.32 & 0.70 & $5(25)$ \\
\hline Malignant & $0.24(0.38)$ & 0.03 & 0.45 & & $15(75)$ \\
\hline Metastatic & $0.37(0.54)$ & $-0.13^{a}$ & 0.87 & 0.23 & $7(47)$ \\
\hline Nonmetastatic & $0.13(0.06)$ & 0.08 & 0.18 & & $8(53)$ \\
\hline \multicolumn{6}{|c|}{ Cutaneous neoplasms } \\
\hline$<3 \mathrm{~cm}$ & $0.11(0.03)$ & 0.03 & 0.19 & 0.16 & $3(30)$ \\
\hline $3-5 \mathrm{~cm}$ & $0.23(0.11)$ & 0.04 & 0.41 & & $4(40)$ \\
\hline$>5 \mathrm{~cm}$ & $0.11(0.68)$ & $-0.06^{a}$ & 0.27 & & $3(30)$ \\
\hline \multicolumn{6}{|l|}{ Healthy dogs } \\
\hline Nonhemolyzed & $0.16(0.06)$ & 0.12 & 0.20 & 0.23 & $12(57)$ \\
\hline Hemolyzed & $0.23(0.18)$ & 0.09 & 0.37 & & $9(43)$ \\
\hline \multicolumn{6}{|l|}{ Oncologic patients } \\
\hline Nonhemolyzed & $0.26(0.43)$ & $-0.01^{a}$ & 0.53 & 0.52 & $12(60)$ \\
\hline Hemolyzed & $0.16(0.08)$ & 0.09 & 0.23 & & $8(40)$ \\
\hline
\end{tabular}

aSPSS calculated value. $\mathrm{SD}=$ Standard deviation, $\mathrm{CI}=$ Confidence interval, $\mathrm{uPA}=$ Urokinase plasminogen activator

important to notice that only five benign tumors were included, which may have influenced our results. Several human cancer reports detected significant differences between patients with benign and malignant mammary [47], ovarian [31], and prostatic [32] tumors, which reinforces the hypothesis that the neoplasm histological type can influence uPA concentrations in serum.

Although the difference between groups was not statistically significant, patients with non-metastatic neoplasms had $65 \%$ lower uPA values than those with metastasis, suggesting that aggressive neoplasms can secrete higher uPA levels into the circulation. As proposed by several authors $[31,32]$, the proteolytic activity of uPA contributes to the ECM degradation allowing for cancer cells to disseminate and metastasize [6-8]. The lack of statistical significance in this series may be due to its small size and/or to the heterogeneity of the included neoplasms. It may otherwise be explained by biological facts such as low secretion of uPA by the included neoplasms, different secretion of uPA by different histological tumor types, and fast uPA metabolization, and/or elimination from the circulation.

The size of the cutaneous neoplasms was also not related to the values of uPA, unlike previously reported in human [48] and veterinary medicine [35].
Once again, the small sample size may justify this discrepancy.

This study also demonstrated that the presence of low levels of hemolysis in serum samples did not influenced the values of uPA. This information might be useful to avoid the rejection of samples with low hemolysis in future studies.

\section{Conclusion}

This study established for the first time the mean serum concentration of uPA in healthy dogs and cancer patients. These preliminary results do not support the use of uPA concentration in serum as a general screening test to identify dogs with cancer. In addition, uPA serum values were also not useful to differentiate patients with benign and malignant neoplasms. However, there was a tendency for dogs with metastatic neoplasms to present higher uPA serum levels. Future research studies should focus on patients with specific tumor types and/or tumors with similar molecular characteristics, to further determine the prognostic and/or predictive value of serum uPA.

\section{Authors' Contributions}

SCR conducted the study. AAS, AJdeM, JNR, and SCR conceived and designed the experiment 
work. SCR, AAS, LRLM, and RRFF collected the samples and clinical data. IV and JNR analyzed the data. AAS and AjdeM revised the manuscript. All authors read and approved the final manuscript.

\section{Acknowledgments}

We gratefully thank UPVet (Veterinary Hospital of the University of Porto), the BSA, the Laboratory of Immunology of ICBAS, the Veterinary Pathology Laboratory of ICBAS, the Cytology Diagnostic Services of ICBAS-UP and the Laboratory of Clinical Analysis and Histopathology of ULHT. We also thank the Biomedical Sciences Institute of Abel Salazar (ICBAS), University of Porto for providing fund support to carry out this research project.

\section{Competing Interests} interests.

The authors declare that they have no competing

\section{References}

1. Schrohl, A.S., Holten-Andersen, M., Sweep, F., Schmitt, M., Harbeck, N., Foekens, J. and Brünner, N. (2003) Tumor markers: From laboratory to clinical utility. Mol. Cell. Proteomics, 2(6): 378-387.

2. Lilja, H., Babaian, R., Dowell, B., Klee, G.G., Rittenhouse, H., Semjonow, A., Shih, I.E.M., Sibley, P. and Sölétormos, G. (2009) Tumor markers in prostate cancer. In: Sturgeon, C.M., Diamandis, E.P., editors. Laboratory Medicine Practice Guidelines - Use of Tumor Markers in Testicular, Prostate, Colorectal, Breast, and Ovarian Cancers. $1^{\text {st }}$ ed. NACB, Washington, DC. p16.

3. Harris, L., Fritsche, H., Mennel, R., Norton, L., Ravdin, P., Taube, S., Somerfield, M.R., Hayes, D.F. and Bast, R.C. (2007) American society of clinical oncology 2007-update of recommendations for the use of tumor markers in breast cancer. J. Clin. Oncol., 25(33): 5287-5312.

4. Ulisse, S., Baldini, E., Sorrenti, S. and D'Armiento, M. (2009) The urokinase plasminogen activator system: A target for anti-cancer therapy. Curr. Cancer Drug Targets, 9(1): 32-71.

5. Lijnen, H.R. (2005) Pleiotropic functions of plasminogen activator inhibitor-1. J. Thromb. Haemost., 3(1): 35-45.

6. Mekkawy, A.H., Pourgholami, M.H. and Morris, D.L. (2014) Involvement of urokinase-type plasminogen activator system in cancer: An overview. Med. Res. Rev., 34(5): 918-956.

7. Andreasen, P.A., Kjøller, L., Christensen, L. and Duffy, M.J. (1997) The urokinase-type plasminogen activator system in cancer metastasis: A review. Int. J. Cancer, 72(1): 1-22.

8. Duffy, M.J. and Duggan, C. (2004) The urokinase plasminogen activator system: A rich source of tumour markers for the individualized management of patients with cancer. Clin. Biochem., 37(7): 541-548.

9. Ferraris, G.M.S. and Sidenius, N. (2013) Urokinase plasminogen activator receptor: A functional integrator of extracellular proteolysis, cell adhesion, and signal transduction. Semin. Thromb. Hemost., 39(4): 347-355.

10. de Munk, G.A.W. and Rijken, D.C. (1990) Fibrinolytic properties of single chain urokinase-type plasminogen activator (pro-urokinase). Fibrinolysis, 4(1): 1-9.

11. Ellis, V. (2003) Plasminogen activators: Structure and function. In: Waisman, D.M., editor. Plasminogen: Structure, Activation, and Regulation. $1^{\text {st }}$ ed. Springer, New York. p19-21.

12. Cines, D.B., Pollak, E.S., Buck, C.A., Loscalzo, J., Zimmerman, G.A., McEver, R.P., Pober, J.S., Wick, T.M., Konkle, B.A. and Schwartz, B.S. (1998) Endothelial cells in physiology and in the pathophysiology of vascular disorders. J. Am. Soc. Hematol., 91(10): 3527-3561.

13. Cozzi, P.J., Wang, J., Delprado, W., Madigan, M.C., Fairy, S., Russell, P.J. and Li, Y. (2006) Evaluation of urokinase plasminogen activator and its receptor in different grades of human prostate cancer. Hum. Pathol., 37(11): 1442-1451.

14. Stepanova, V.V. and Tkachuk, V.A. (2002) Urokinase as a multidomain protein and polyfunctional cell regulator. Biochemistry, 67(1): 109-118.

15. Foekens, J.A., Peters, H.A., Look, M.P., Portengen, H., Schmitt, M., Kramer, M.D., Brunner, N., Jänicke, F., Meijervan Gelder, M.E. and Henzen-Logmans, S.C. (2000) The urokinase system of plasminogen activation and prognosis in 2780 breast cancer patients. Cancer Res., 60(3): 636-643.

16. Harbeck, N., Kates, R.E. and Schmitt, M. (2002) Clinical relevance of invasion factors urokinase-type plasminogen activator and plasminogen activator inhibitor Type 1 for individualized therapy decisions in primary breast cancer is greatest when used in combination. J. Clin. Oncol., 20(4): 1000-1007.

17. Look, M.P., van Putten, W.L.J., Duffy, M.J., Harbeck, N., Christensen, I.J., Thomssen, C., Kates, R., Spyratos, F., Fernö, M., Eppenberger-Castori, S., Sweep, C.G. and Ulm, K. (2002) Pooled analysis of prognostic impact of urokinase-type plasminogen activator and its inhibitor PAI-1 in 8377 breast cancer patients. $J$. Natl. Cancer Inst., 94(2): 116-128.

18. Harbeck, N., Schmitt, M., Meisner, C., Friedel, C., Untch, M., Schmidt, M., Sweep, C.G.J., Lisboa, B.W., Lux, M.P., Beck, T., Hasmüller, S., Kiechle, M. and Jänicke, F. (2013) Ten-year analysis of the prospective multicenter Chemo-N0 trial validates American society of clinical oncology (ASCO)-recommended biomarkers uPA and PAI-1 for therapy decision making in node-negative breast cancer patients. Eur. J. Cancer, 49(8): 1825-1835.

19. Margheri, F., D'Alessio, S., Serratí, S., Pucci, M., Annunziato, F., Cosmi, L., Liotta, F., Angeli, R., Angelucci, A., Gravina, G.L. and Rucci, N. (2005) Effects of blocking urokinase receptor signaling by antisense oligonucleotides in a mouse model of experimental prostate cancer bone metastases. Genet. Ther., 12(8): 702-714.

20. Sawai, H., Liu, J., Reber, H.A., Hines, O.J. and Eibl, G. (2006) Activation of peroxisome proliferator-activated receptor-gamma decreases pancreatic cancer cell invasion through modulation of the plasminogen activator system. Mol. Cancer Res., 4(3): 159-167.

21. Kobayashi, H., Sugino, D., She, M.Y., Ohi, H., Hirashima, Y., Shinohara, H., Fujie, M., Shibata, K. and Terao, T. (1998) A bifunctional hybrid molecule of the amino-terminal fragment of urokinase and domain II of bikunin efficiently inhibits tumor cell invasion and metastasis. Eur. J. Biochem., 253(3): 817-826.

22. Szende, B., Okada, Y., Tsuda, Y., Horvath, A., Bökönyi, G., Okamoto, S., Wanaka, K. and Keri, G. (2002) A novel plasmin-inhibitor inhibits the growth of human tumor xenografts and decreases metastasis number. In Vivo, 16(5): 281-286.

23. Ploug, M., Østergaard, S., Gårdsvoll, H., Kovalski, K., HolstHansen, C., Holm, A., Ossowski, L. and Dano, K. (2001) Peptide-derived antagonists of the urokinase receptor-affinity maturation by combinatorial chemistry, identification of functional epitopes, and inhibitory effect on cancer cell intrastation. Biochemistry, 40(40): 12157-12168.

24. Hu, X.W., Duan, H.F., Pan, S.Y., Li, Y.M., Xi, Y., Zhao, S.R., Yin, L., Li, J.F., Chen, H.P. and Wu, C.T. (2016) Inhibition of tumor growth and metastasis by ATF-Fc, an engineered antibody targeting urokinase receptor. Cance Biol. Ther., 7(5): 651-659.

25. Pluijm, G., Sijmons, B., Vloedgraven, H., van der Bent, C., Drijfhout, J.W., Verheijen, J., Quax, P., Karperien, M., Papapoulos, S. and Löwik, C. (2001) Urokinase-receptor/ 
integrin complexes are functionally involved in adhesion and progression of human breast cancer in vivo. Am. J. Pathol., 159(3): 971-982.

26. Vallera, D.A., Li, C., Jin, N., Panoskaltsis-Mortari, A. and Hall, W.A. (2002) Targeting urokinase-type plasminogen activator receptor on human glioblastoma tumors with diphtheria toxin fusion protein DTAT. J. Natl. Cancer Inst., 94(8): 597-606.

27. Rønø, B., Rømer, J., Liu, S., Bugge, T.H., Leppla, S.H. and Kristjansen, P.E.G. (2006) Antitumor efficacy of a urokinase activation-dependent anthrax toxin. Mol. Cancer Ther., 5(1): 89-96.

28. Su, S.C., Lin, C.W., Yang, W.E., Fan, W.L. and Yang, S.F. (2015) The urokinase-type plasminogen activator (uPA) system as a biomarker and therapeutic target in human malignancies. Expert Opin. Ther. Targets, 20(5): 551-566.

29. Strojan, P., Budihna, M., Šmid, L., Vrhovec, I. and Škrk, J. (1998) Urokinase-type plasminogen activator (uPA) and plasminogen activator inhibitor Type 1 (PAI-1) in tissue and serum of head and neck squamous cell carcinoma patients. Eur. J. Cancer, 34(8): 1193-1197.

30. Konukoglu, D., Turhan, M.S., Celik, V. and Turna, H. (2007) Relation of serum vascular endothelial growth factor as an angiogenesis biomarker with nitric oxide and urokinase-type plasminogen activator in breast cancer patients. Indian J. Med. Res., 125(6): 747-751.

31. Zhang, W., Ling, D., Tan, J., Zhang, J. and Li, L. (2013) Expression of urokinase plasminogen activator and plasminogen activator inhibitor Type-1 in ovarian cancer and its clinical significance. Oncol. Rep., 29(2): 637-645.

32. Miyake, H., Hara, I., Yamanaka, K., Gohji, K., Arakawa, S. and Kamidono, S. (1999) Elevation of serum levels of urokinase-type plasminogen activator and its receptor is associated with disease progression and prognosis in patients with prostate cancer. Prostate, 39(2): 123-129.

33. Santos, A., Lopes, C., Marques, R.M., Amorim, I., Ribeiro, J., Frias, C., Vicente, C., Gärtner, F. and de Matos, A. (2010) Immunohistochemically analysis of urokinase plasminogen activator and its prognostic value in canine mammary tumours. Vet. J., 189(1): 43-48.

34. Santos, A.A., Lopes, C.C., Ribeiro, J.R., Martins, L.R., Santos, J.C., Amorim, I.F., Gärtner, F. and Matos, A.J. (2013) Identification of prognostic factors in canine mammary malignant tumours: A multivariable survival study. BMC Vet. Res., 9(1): 1-11.

35. Golshahi, H., Tavasoly, A., Rezaie, A. and Farhadi, M. (2013) Urokinase plasminogen activator expression in canine malignant mammary tumours by immunohistochemically study. Bull. Vet. Inst. Pulawy, 57(4): 587-591.

36. Schappa, J.T., Frantz, A.M., Gorden, B.H., Dickerson, E.B., Vallera, D.A. and Modiano, J.F. (2013) Hemangiosarcoma and its cancer stem cell subpopulation are effectively killed by a toxin targeted through epidermal growth factor and urokinase receptors. Int. J. Cancer, 133(8): 1936-1944.
37. Anwar, S., Yanai, T. and Sakai, H. (2015) Immunohistochemical detection of urokinase plasminogen activator and urokinase plasminogen activator receptor in canine vascular endothelial tumours. J. Comp. Pathol., 153: $278-282$.

38. Faleiro, M.R., Toledo, D.C., Rodrigues, M.M.P., Amorim, R.L., Brito, L.A.B., Damasceno, A.D. and Moura, V.M.B.D. (2013) uPAR expression in canine normal prostate and with proliferative disorders. Cienc. Anim. Bras., 14(2): 237-244.

39. Leonardi, L., Quattrini, I., Roperto, F. and Benassi, M.S. (2013) Protease expression in giant cell tumour of bone: A comparative study on feline and human samples. Res. Vet. Sci., 95(2): 310-315.

40. Diez, M. and Nguyen, P. (2006) Obesity: Epidemiology, pathophysiology and management of the obese dog. In: Pibot, P., Biourge, V., Elliot, D., editors. Encyclopedia of Canine Clinical Nutrition. $1^{\text {st }}$ ed. Aniwa SAS, France. p22.

41. Cobos, E., Jumper, C. and Lox, C. (2003) Pretreatment determination of the serum urokinase plasminogen activator and its soluble receptor in advanced small-cell lung cancer or non-small-cell lung cancer. Clin. Appl. Thromb. Hemost., 9(3): 241-246.

42. Gibbs, J.F., Schlieman, M., Singh, P., Saxena, R., Martinick, M., Hutson, A.D. and Corasanti, J. (2009) A pilot study of urokinase-type plasminogen activator (uPA) overexpression in the brush cytology of patients with malignant pancreatic or biliary strictures. HPB Surg., 2009: Article ID: 805971, 5.

43. Winter, K., Szcześniak, P., Bulska, M., KumorKisielewska, A., Durko, L., Gąsiorowska, A., OrszulakMichalak, D. and Małecka-Panas, E. (2015) Serum level of urokinase plasminogen activator (uPA) correlates with the survival of patients with pancreatic ductal adenocarcinoma (PDAC). Pancreact. Disord. Ther., 5(3): 1-6.

44. Gustafsson, A., Ajeti, V. and Ljunggren, L. (2011) Detection of supAR in the saliva of healthy young adults: Comparison with plasma levels. Biomark Insights, 6: 119-125.

45. Yu, L., Long, D., Wu, X.L., Yang, J.H., Yang, Y.C., Feng, G. and Li, Y. (2011) Prognostic significance of urokinase-type plasminogen activator and its receptor in patients with systemic inflammatory response syndrome. World J. Emerg. Surg., 2(3): 185-189.

46. Maguire, T., Chin, D., Soutar, D. and Duffy, M.J. (2000) Low levels of urokinase plasminogen activator components in basal cell carcinoma of the skin. Int. J. Cancer, 85(4): 457-459.

47. Dublin, E., Hanby, A., Patel, N.K., Liebman, R. and Barnes, D. (2000) Immunohistochemical expression of uPA, uPAR, and PAI-1 in breast carcinoma. Am. J. Pathol., 157(4): 1219-1227.

48. Narod, S.A. (2012) Tumour size predicts long-term survival among women with lymph node-positive breast cancer. Curr. Oncol., 19(5): 249-253. 